\title{
Driving Factors for the Change of Fertilizer Use Intensity in China and Its Six Major Regions
}

\author{
Huimin $\mathrm{Qu}^{1}, \&$ Jie $\mathrm{Han}^{2}$ \\ ${ }^{1}$ School of Business, Yantai Institute of Science and Technology, Yantai 265600, China \\ Correspondence: Huimin Qu, School of Business, Yantai Institute of Science and Technology, Yantai 265600, \\ China.
}

Received: August 13, 2021

Accepted: August 31, 2021

Online Published: September 8, 2021

doi:10.5539/ibr.v14n10p71

URL: https://doi.org/10.5539/ibr.v14n10p71

\begin{abstract}
China has invested excessive amounts of fertilizer on limited farmland, which poses a threat to human health and agro-ecological environment. While a plethora of studies have explored how to reduce the total amount of chemical fertilizer, and scant attention has been paid to how to reduce the chemical fertilizer use intensity (FUI). This paper aims to explore the driving factors for the change of FUI to answer this question. It uses the official statistics of China from 1997 to 2017, as well as index decomposition analysis (IDA) and Laspeyres index decomposition method to obtain the following results. The change of fertilizer use intensity can be affected by three factors: input-output ratio of fertilizer (IOR), unit labor output (ULO) and labor input per unit sown area (LIU). At the national level, IOR is the most important factor in reducing the use of chemical fertilizers, while ULO is the most important factor in increasing. The factor of LIU can not only reduce the intensity of fertilizer use, but also increase the intensity. On a regional level, the fertilizer use intensity in Central-South China is the strongest, while that in the Southwest China is the smallest. Compared with other regions, the factors of ULO in Northwest China and IOR in East China have the greatest impact on fertilizer use intensity. In addition, LIU mainly reduces the intensity of fertilizer use in Northeast China, while this factor in North China is to increase the intensity. Our findings suggest that farmers should not increase labor productivity by investing chemical fertilizer. Improving the efficiency of fertilizer use and transferring rural labor force can reduce the fertilizer use intensity in China.
\end{abstract}

Keywords: chemical fertilizer use intensity, IDA, Laspeyres index decomposition, input-output ratio, labor productivity, labor input, China

\section{Introduction}

China is one of the countries with the largest fertilizer use intensity (FUI) in the world. From 2002 to 2016, the fertilizer use intensity in China was much higher than that in the United States, Canada, Japan, Australia, Brazil, India and the European Union (Fig.1). A rich body of literatures have confirmed that chemical fertilizer can increase crop yield (Stewart et al., 2005), but excessive use of fertilizers can also reduce the fertilizer use efficiency (Tilman et al., 2001), and bring many harmful factors: endangering human health (Ma et al., 2012), polluting soil, water and atmosphere (Guo et al., 2010; Ju et al., 2009; Snyder et al., 2009; Van Damme et al., 2018), enhancing atmospheric nitrogen deposition (Liu et al., 2013), and threatening the agricultural sustainability (Coomes et al., 2019). In order to solve these problems, China launched the "Action Plan for the Zero Increase of Fertilizer Use" in 2015 and adopted a series of measures to reduce the use of chemical fertilizers (Cui et al., 2018; Lu et al., 2019; Zhang et al., 2016), which has reduced the fertilizer use in China. However, China's current fertilizer use intensity is still three times more than that of the world (Fig.1). China needs to reduce not only the total amount of fertilizer used, but also the intensity of fertilizer use. Therefore, it is necessary to identify and quantify the driving factors to reduce fertilizer use intensity. 


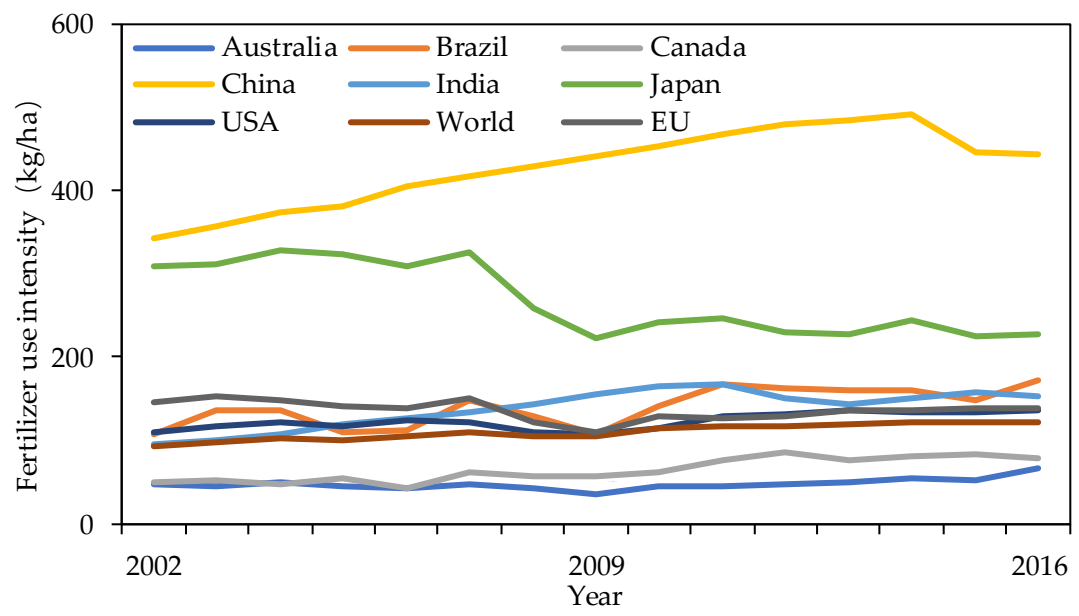

Figure 1. Fertilizer use intensity for major countries and organizations in the world from 2002-2016

The intensity of fertilizer use is the amount of fertilizer used per area of cropland. The use of chemical fertilizer includes three nutrients: $\mathrm{N}, \mathrm{P}_{2} \mathrm{O}_{5}$ and $\mathrm{K}_{2} \mathrm{O}$.

(Sources: http://www.fao.org/faostat/en/\#data.)

Previous studies have conducted beneficial explorations on why should reduce fertilizer consumption and how to reduce the fertilizer consumption. In order to prove the necessity of reducing the use of chemical fertilizers, a large and growing body of literature has investigated why the chemical fertilizer use should be reduced. These researches have shown that although fertilization can increase crop yield (Ayoola and Adeniyan, 2006; Stewart et al., 2005), excessive fertilization can also reduce crop yield (Vanlauwe and Giller, 2006), and threaten agricultural ecological environment (Atafar et al., 2010; Mosier et al., 2013; Savci, 2012) and human health (Majumdar and Gupta, 2000; Prasad, 1998; Zhang et al., 2018; Zhu and Chen, 2002). Meanwhile, several literatures have pointed out that China's reduction in fertilizer consumption has zero impact on crop yields (Ju et al., 2009; Smith and Siciliano, 2015). As the deterioration of the agro-ecological environment, scholars are paying more attention to how to reduce the fertilizer consumption (Smith and Siciliano, 2015). They have been answered this question from technological innovation aspect and socioeconomic aspect (Ju et al., 2016). In terms of technological innovation aspect, researchers often compare the current level of agricultural production with the advanced production methods in a country. They believe that the comprehensive management of crop-soil-nutrient (Chen et al., 2014; Zhang et al., 2013), the use of new fertilizers (Chien et al., 2009) and the improvement of fertilization methods (Rahman and Zhang, 2018) not only increase the yield, but enhance the efficiency of nutrient absorption and reduce the use of chemical fertilizers. In terms of social economy, the factors affecting fertilizer consumption have been extensively studied. These findings are based on economic research methods such as qualitative analysis and quantitative research, and suggest that the use of fertilizers can be reduced by adjusting crop planting types (Chen et al., 2018), eliminating fertilizer subsidies (Jayne et al., 2013; Mustapha and Said, 2016; Zhang et al., 2013), expanding farm size (Ju et al., 2016; Wu et al., 2018), and promoting agricultural training and extension services (Li et al., 2013; Sun et al., 2012).

While scholars have made abundant study for the influencing factors of the fertilizer consumption, scant attention has been paid to the drivers of fertilizer use intensity in China (Cai et al., 2018; Pan, 2014; ZHENG and XU, 2017). A handful of literatures have examined two driving factors of efficiency and structure, but other factors related to socio-economic factors have not been studied. Particularly, scholars hold different views on the impact of agricultural labor input on the chemical fertilizers use. Some scholars believe that expanding farm scale can reduce fertilizer use, local farmers to work non-agricultural or migrate to cities can expand farm size, So as to reduce the use of fertilize (Ma et al., 2014). On the contrary, there is also a view that the shortage of labor makes it difficult to transport organic fertilizer to the fields, which in turn increases the chemical fertilizer use (Chadwick et al., 2012). However, these phenomena have not been tested in terms of driving factors for the change of fertilizer use intensity. Moreover, previous researches only explored the driving factors from the perspective of a country or a region, but ignored the comparison between different regions within a country. Studies have shown that there are large regional variation in China's fertilizer input costs (Ma et al., 2012). Therefore, it is necessary to explore the driving factors for the change of fertilizer use intensity at the regional 
and national level.

This study aims to explore the driving factors of fertilizer use intensity by index decomposition analysis (IDA) and Laspeyres exponential decomposition method. At the same time, the driving factors of fertilizer use intensity from different regions will be investigated by the research. This paper expands the scope of previous studies on driving factors of fertilizer use intensity, especially on the impact of labor input on fertilizer use intensity. In addition, it provides a reference for the implementation of differentiation policy by comparing the driving factors in different regions.

\section{Materials and Methods}

2.1 Regional Division

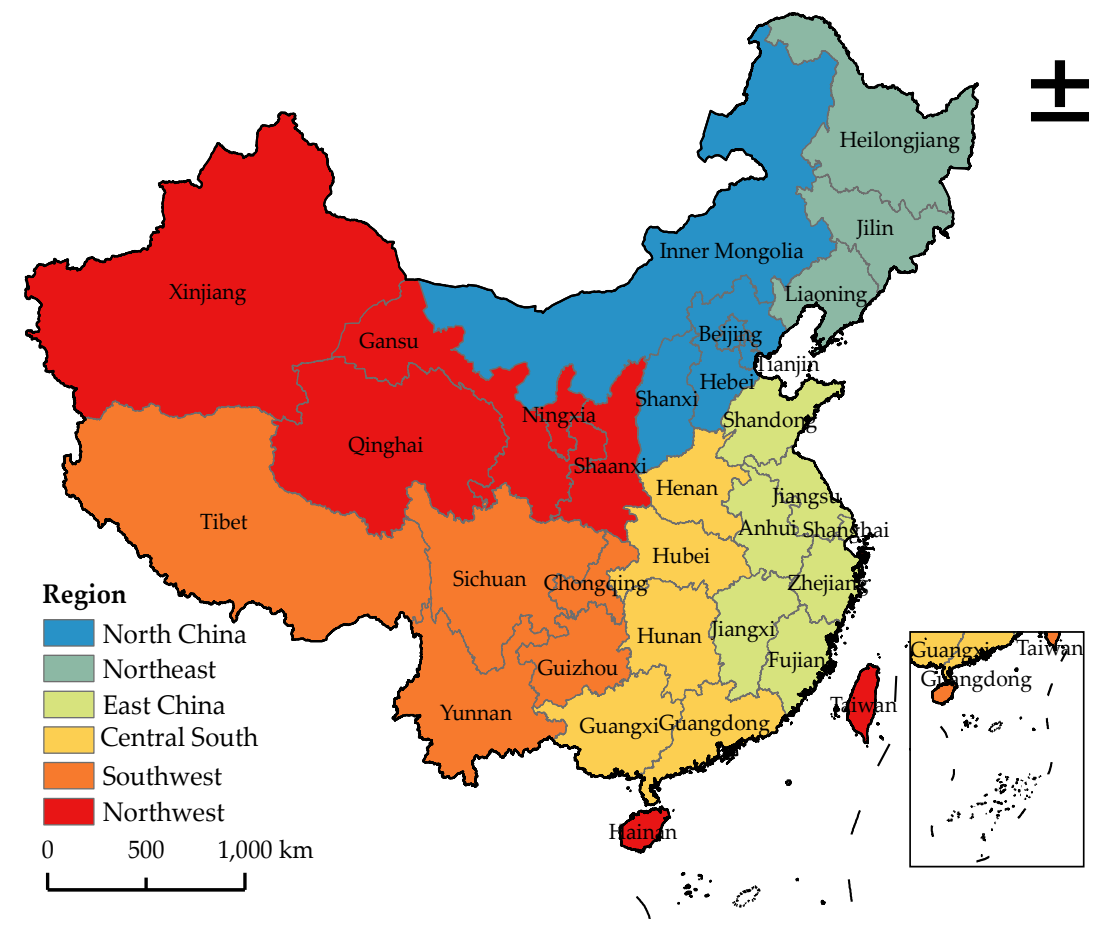

Figure 2. Division of six regions in China

China has a vast territory, spanning six major temperature zones, and its topography is high in the west and low in the east. It makes Chinese soil type and crop planting structure different from region to region. This also leads to great differences in fertilization intensity in different regions of China. Considering these heterogeneities, this paper divides 31 provincial administrative regions (excluding Hong Kong, Macao and Taiwan) into six regions (Figure 2): North China (NC) consists 5 Provinces such as Beijng, Tianjing, Hebei, Shanxi, Inner Mongolia. Northeast China (NE) has 3 Provinces which are Heilongjiang, Jilin, Liaoning Provinces. East China (EC) has 7 Provinces which are Shandong, Jiangsu, Shanghai, Anhui, Zhejiang, Fujian, Jiangxi. Central-South China (CS) has 6 Provinces which are Henan, Hubei, Hunan, Guangdong, Guangxi, Hainan. Southwest China (SW) has 5 Provinces which are Sichuan, Chongqing, Guizhou, Yunnan, Tibet. Northwest China (NW) has 5 Provinces which are Shaanxi, Ningxia, Gansu, Qinghai, Xinjiang Provinces. These six regions have significant differences in crop structure, topography, climate conditions, technological level and many other factors that closely related to agricultural production. Therefore, this paper will analyze the driving factors of the change for the fertilizer use intensity from the country and regional levels.

\subsection{Methods}

\subsubsection{Index Decomposition Analysis}

This paper uses IDA method to decompose fertilizer utilization intensity into three effects: input-output ratio of fertilizer (IOR, $\left.E^{t}=F^{t} / Y^{t}\right)$, unit labor output $\left(\mathrm{ULO}, P^{t}=Y^{t} / L^{t}\right)$, and labor inputs per unit sown area $\left(\mathrm{LIU}, L^{t}=L^{t} / S^{t}\right)$. Among them, F represents fertilizer consumption, Y represents agricultural output value, $L$ represents labor input, and $\mathrm{S}$ represents land input. All three factors have clear economic implications: IOR represents fertilization 
efficiency, ULO represents labor productivity, LIU represents labor input. The abbreviations and its explanations of these three driving factors are shown in Table 1.

$$
\frac{F^{t}}{S^{t}}=\frac{F^{t}}{Y^{t}} \cdot \frac{Y^{t}}{L^{t}} \cdot \frac{L^{t}}{S^{t}}=E^{t} \cdot P^{t} \cdot L^{t}
$$

Table 1. List of abbreviations

\begin{tabular}{cl}
\hline Abbreviations & Explanation of Abbreviations \\
\hline IOR & input-output ratio of fertilizer \\
ULO & unit labor output \\
LIU & labor input per unit sown area \\
\hline
\end{tabular}

\subsubsection{Laspeyres Index Decomposition Method}

In order to further investigate the driving factors of the change for the fertilizer use intensity, this paper uses the Laspeyres exponential decomposition method to decompose the variation of fertilization intensity according to the above three effects. Sun (1998) first proposed the laspeyre exponential decomposition method based on perfect decomposition, this method is widely used to study the driving factors of economic development, carbon emission and energy consumption

The change of fertilizer use intensity from stage 0-t can be decomposed into IOR effect $\left(E^{\prime}\right)$, ULO effect $\left(P^{\prime}\right)$ and LIU effect $\left(L^{\prime}\right)$ by formula (2), and the formula (3) is the detailed decomposition process of Laspeyres exponential decomposition.

$$
\begin{aligned}
& \Delta F=F^{t}-F^{0}=E^{\prime}+P^{\prime}+L^{\prime} \\
\Delta F=F^{t}-F^{0} & E^{t} \cdot P^{t} \cdot L^{t}-E^{0} \cdot P^{0} \cdot L^{0} \\
= & \Delta E \cdot P^{0} \cdot L^{0}+\Delta P \cdot E^{0} \cdot L^{0}+\Delta L \cdot E^{0} \cdot P^{0} \\
+ & \Delta E \cdot \Delta P \cdot L^{0}+\Delta E \cdot \Delta L \cdot P^{0}+\Delta P \cdot \Delta L \cdot E^{0}+\Delta E \cdot \Delta P \cdot \Delta L
\end{aligned}
$$

According to the principle of equal allocation (Sun, 1998), the change of fertilizer use intensity can be completely decomposed. Formula (4-6) represents three effects that affect the change in fertilizer use intensity: IOR effect, ULO effect, and LIU effect.

$$
\begin{gathered}
E^{\prime}=\Delta E \cdot P^{0} \cdot L^{0}+\frac{1}{3} \Delta E \cdot \Delta P \cdot \Delta L+\frac{1}{2}\left(\Delta E \cdot \Delta P \cdot L^{0}+\Delta E \cdot \Delta L \cdot P^{0}\right) \\
P^{\prime}=\Delta P \cdot E^{0} \cdot L^{0}+\frac{1}{3} \Delta E \cdot \Delta P \cdot \Delta L+\frac{1}{2}\left(\Delta P \cdot \Delta E \cdot L^{0}+\Delta P \cdot \Delta L \cdot E^{0}\right) \\
L^{\prime}=\Delta L \cdot E^{0} \cdot P^{0}+\frac{1}{3} \Delta E \cdot \Delta P \cdot \Delta L+\frac{1}{2}\left(\Delta L \cdot \Delta E \cdot P^{0}+\Delta L \cdot \Delta P \cdot E^{0}\right)
\end{gathered}
$$

Formula (7) can further calculate the contribution rate of each effect change to the change of fertilizer use intensity. In formula (7), $e, p, l$ are respectively the contribution rates of input-output ratio effect of fertilizer, labor productivity effect and unit sown area labor input effect to fertilization intensity change. If the contribution rate of a certain driving factor is positive, the change direction of this factor is the same as that of fertilizer use intensity, and if the contribution rate is negative, the change direction is opposite to that of fertilizer use intensity. In addition, $E^{\prime}, P^{\prime}$ and $L^{\prime}$ are divided by the base period fertilizer use strength to obtain a growth rate relative to the base period fertilizer use intensity: $e^{\prime}, p^{\prime}$ and $l^{\prime}$ (formula 8). 


$$
\begin{aligned}
& e=\frac{E^{\prime}}{\Delta F} ; \quad p=\frac{P^{\prime}}{\Delta F} ; \quad l=\frac{L^{\prime}}{\Delta F} \\
& e^{\prime}=\frac{E^{\prime}}{F^{0}} ; \quad p^{\prime}=\frac{P^{\prime}}{F^{0}} ; \quad l^{\prime}=\frac{L^{\prime}}{F^{0}}
\end{aligned}
$$

\subsection{Data Source}

The data used in this paper is from 1997-2017. The indicators include: (1) fertilizer use intensity ( $\mathrm{kg} / \mathrm{ha}$, including the use intensity of nitrogen fertilizer, phosphate fertilizer, potassium fertilizer, and compound fertilizer). This indicator is expressed as the ratio of the amount of fertilizer applied to the total sown area of crops; (2) the input-output ratio of fertilizer $(\mathrm{kg} / 10,000 \mathrm{CNY})$. Expressed by the proportion of fertilization to the total agricultural output value; (3) labor productivity (10,000CNY/person). Expressed by the ratio of total agricultural output to agricultural employees. In detail, agricultural workers are replaced by the primary industry employees multiplied by the total agricultural output value of the total output value of agriculture, forestry, animal husbandry and fishery (HUANG et al., 2005); (4) labor input (person/ha). Expressed by the number of labor inputs per unit sown area. All the data derived from China Statistical Yearbook, China Rural Statistical Yearbook and the provincial statistical yearbooks. In addition, we use the interpolation method to fill up the missing data of primary industry practitioners in Hebei and Heilongjiang Province in 2017.

Table 2 provides descriptive statistics for these indicators. From the average level, the fertilizer use intensity in North China, East China and South China is higher than the national average, while the rest of the region is lower than the national average, the reason is that East China, North China and Central South China are the main grain producing areas and population areas in China. It is necessary to rely on the application of large amount of fertilizer to ensure food security. Simultaneously, the IOR in North, Northeast and Central-South China, labor productivity in North, Northeast and East China, and LIU in South, Southwest and Northwest China are higher than the national average. From the annual average growth rate, the fertilizer use intensity and ULO of the whole country increased by $2.19 \%$ and $3.15 \%$ annually, while the IOR and LIU decreased by $0.74 \%$ and $0.78 \%$ annually.

\begin{tabular}{|c|c|c|c|c|c|c|c|c|}
\hline \multirow{2}{*}{ Regions } & \multicolumn{4}{|c|}{ Annual average } & \multicolumn{4}{|c|}{ Average annual growth rate $(\%)$} \\
\hline & FUI & IOR & ULO & LIU & FUI & IOR & ULO & LIU \\
\hline Nathional & 321.47 & 224.48 & 1.70 & 1.07 & 2.19 & -0.74 & 3.15 & -0.78 \\
\hline $\mathrm{NC}$ & 348.10 & 227.15 & 2.30 & 0.83 & 2.52 & -0.51 & 2.68 & -0.23 \\
\hline $\mathrm{NE}$ & 272.13 & 228.71 & 2.18 & 0.59 & 1.18 & -0.83 & 2.81 & -0.76 \\
\hline $\mathrm{EC}$ & 370.15 & 207.21 & 2.25 & 0.99 & 1.54 & -1.02 & 3.45 & -0.93 \\
\hline CS & 392.59 & 235.91 & 1.49 & 1.23 & 2.86 & -0.78 & 3.07 & -0.23 \\
\hline SW & 218.84 & 203.30 & 0.84 & 1.47 & 1.80 & -0.45 & 3.44 & -1.25 \\
\hline NW & 273.59 & 250.93 & 1.17 & 1.15 & 2.81 & -0.72 & 3.72 & -0.99 \\
\hline
\end{tabular}

Table 2. Descriptive statistics

\section{Results}

\subsection{The Change of Fertilizer Use Intensity}

Figure 3 shows the changing trend of the total fertilizer use intensity and the use intensity of nitrogen, phosphorus, potassium and compound fertilizers. From 1997 to 2017, the average fertilizer use intensity in China increased from $247.11 \mathrm{~kg} / \mathrm{ha}$ to $381.05 \mathrm{~kg} / \mathrm{ha}$. Regionally, with the fastest increase in the Central-South China, fertilizer use intensity in all six regions showed an upward trend. The fertilizer use intensity in North China, East China and Southeast China is higher than the national average, while the rest is lower than the national average. In addition, the intensity of fertilizer use in Northeast China has declined in 2017, and the fertilizer use intensity in North China and Southwest China has not increased, while East China, Central-South China and Northwest China are still rising. Therefore, North China, Central-South China and Northwest China should be considered as 
a key area for reducing the intensity of fertilizer use.

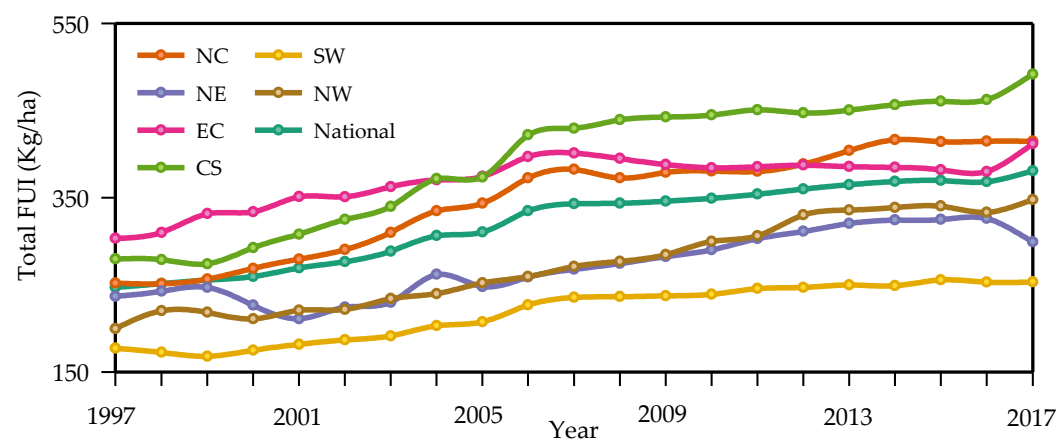

(a)

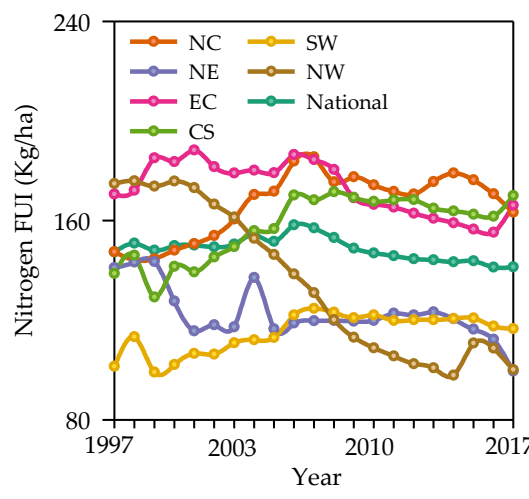

(b)

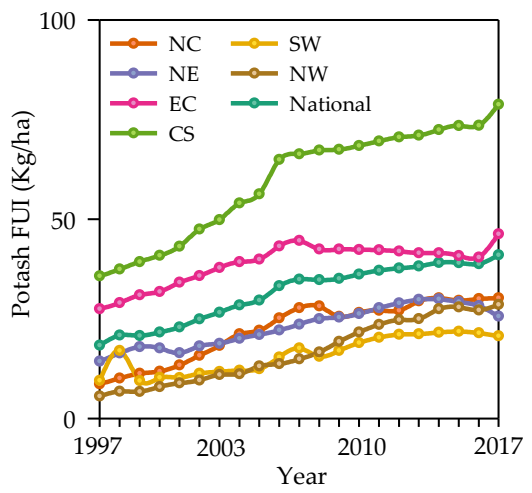

(d)

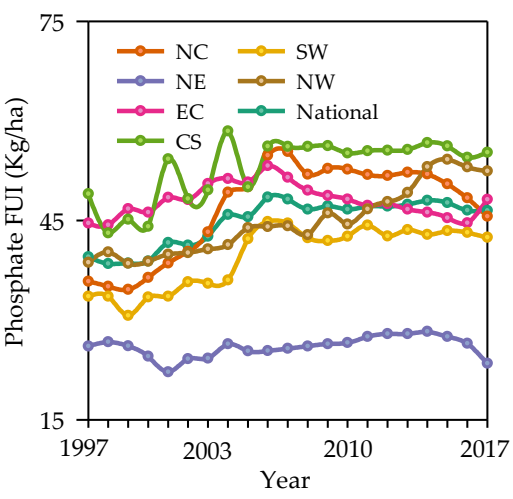

(c)

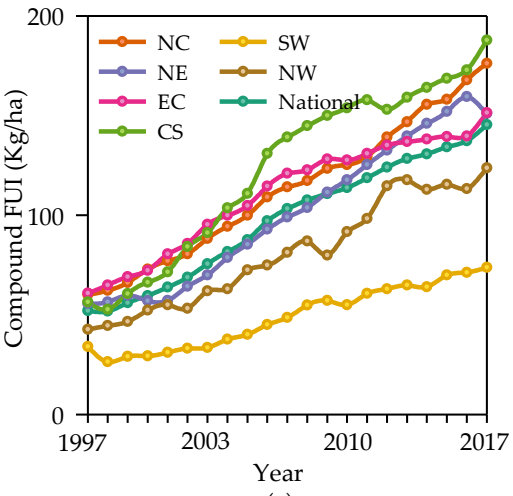

(e)

Figure 3. (a) Overall fertilizer use intensity. (b) Nitrogen fertilizer use intensity. (c) Phosphate fertilizer use intensity (d) Potassium fertilizer use intensity (e) Compound fertilizer use intensity.

The above national and regional data are the average of the provinces.

Different regions and different types of fertilizer use intensity have significant differences. From the national level, the fertilization intensity of nitrogen fertilizer and phosphate fertilizer increased first and then decreased during 1997-2017, while the fertilization intensity of potash fertilizer and compound fertilizer increased. From the regional level, the fertilization intensities of nitrogen, phosphorus, potash and compound fertilizers are higher in the Central-South China, while those of nitrogen, phosphate, potash and compound fertilizers are lower in the Southwest China. The fertilizer use intensity of nitrogen fertilizer decreased obviously, especially in Northwest China, from the highest in 1997 (177.78 kg/ha) to the lowest in $2017(100.11 \mathrm{~kg} / \mathrm{ha})$. The use intensity of phosphate, potash and compound fertilizers in various regions showed an upward trend and the increase in the use intensity of compound fertilizer was the most obvious. In addition, reducing the use intensity of compound fertilizer can simultaneously reduce the excessive input of nutrients N, P2O5 and K2O per unit sown area. Therefore, China should take necessary measures to control the increasing of compound fertilizer use intensity. 


\subsection{Driving Factors for the Change of Fertilizer Use Intensity}

\subsubsection{National Level Analysis}

The main reason for the $54.20 \%$ increase in fertilizer use intensity in China from 1997 to 2017 is the continuous improvement of labor productivity (Figure 4). Without the influence of other factors, the increase of ULO increased the fertilizer use intensity by $50.33 \%, 41.41 \%$ and $7.61 \%$ in 1997-2004, 2004-2011 and 2011-2017, respectively. The average contribution rate of this factor to the increase of fertilizer use intensity was $285.79 \%$. This result shows that the improvement of labor productivity can promote the increase of fertilizer use intensity in China. A large part of the improvement of agricultural labor productivity in China is achieved by investing a large amount of fertilizer(Murgai, 1999). Labor productivity effect promotes the increase in fertilizer use intensity, while the fertilization efficiency inhibits the use intensity of fertilizer. As shown in Figure 5, The IOR effect decreased the fertilizer use intensity by $10.50 \%, 14.75 \%$, and $24.20 \%$, respectively, between 1997-2004, 20042011 and 2011-2017. This result indicates that the decline in the IOR of fertilizer is the most important factor in inhibiting the increase in fertilizer use intensity. The effect of LIU on the increase of fertilizer use intensity in China was first inhibited and then promoted. With other factors unchanged, LIU reduced fertilizer use intensity by $15.79 \%$ in $1997-2004$, and by $11.38 \%$ in $2004-2011$. However, from 2011-2017, LIU increased fertilization intensity by $2.80 \%$.

Liu and IOR have different effects on inhibiting the growth of chemical fertilizer intensity, and the inhibitory effect of IOR effect is becoming more and more obvious. The reason is that the decline rate of input-output ratio of chemical fertilizer in China, that is, the improvement rate of chemical fertilizer efficiency exceeds the reduction rate of labor input per unit land, reflecting the continuous improvement of the technical level of agricultural production in China, And continue to play an important role in curbing the growth of chemical fertilizer.

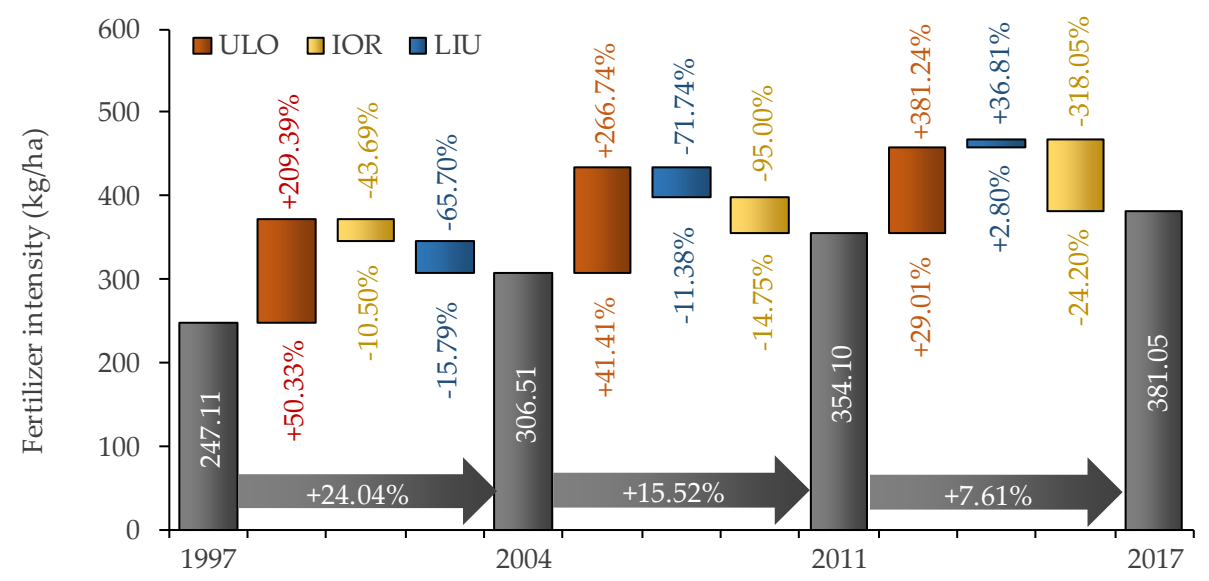

Figure 4. Driving factors of change in fertilizer use intensity during the period 2003-2003, 2003-2009 and 2009-2017

The number above the color bars is the contribution of the three effects to the change in fertilizer use intensity, and the lower number is the growth rate relative to the initial year.

\subsubsection{Regional Level Analysis}

To explore the drivers of fertilizer use intensity changes at the regional level, we further measured the driving factors for the change of fertilizer use intensity in North China, Northeast China, East China, Central-South China, Southwest China and Northwest China (Figure 5). The contribution rate of labor productivity to the increase of fertilizer use intensity is positive, which shows that the increase of labor productivity is the main driving factor of the increase of fertilizer use intensity. From 1997-2017, labor productivity in North China, Northeast, East China, Central-South China, Southwest and Northwest increased fertilizer use intensity by $95.35 \%, 112.36 \%, 131.52 \%$, $117.80 \%, 123.53 \%$ and $141.70 \%$, respectively. According to Figure 5, the effect of ULO increases the intensity of fertilizer use in the six regions, indicating that the increase in labor productivity has invested a large amount of fertilizer. However, there are obvious differences in IOR and LIU effects on the change of fertilizer use intensity in different regions, which are as follows:

(1) The fertilizer use intensity in North China increased by $32.91 \%, 13.49 \%$ and $9.14 \%$ in $1997-2004,2004$ 2011 and 2011-2017, respectively (Fig. 5a). The reduction of LIU in 2004-2011 increased the fertilizer use 
intensity by $36.03 \mathrm{~kg} / \mathrm{ha}$, which is equivalent to $18.10 \%$ in 2004 . However, the fertilizer use intensity increased by $16.71 \%$ in 2011-2017. In addition, the decreasing effect of IOR reduces the fertilizer use intensity in North China.

(2) The fertilizer use intensity in Northeast China decreased by 1.23\% from 2011 to 2017 (Fig. 5b). The effect of IOR and LIU help to reduce the fertilizer use intensity in Northeast China from 1997-2017. Meanwhile, we also issued that the continuous improvement of fertilization efficiency has gradually become the most important factor to reduce the fertilizer use intensity in Northeast China.

(3) The effect of IOR in Eastern China reduced fertilizer use intensity by $15.50 \%$ in 1997, $21.16 \%$ in 2004 and $27.35 \%$ in 2011 respectively in 1997-2004, 2004-2011 and 2011-2017 (Fig. 5c). In addition, the effect of LIU reduced fertilization intensity by $14.72 \%$ in $1997-2004$ and $24.45 \%$ in $2004-2011$, respectively. However, this effect increased fertilizer use intensity by $4.66 \%$ in $2011-2017$.

(4) The effects of $\mathrm{E}$ and $\mathrm{L}$ on the fertilization intensity in Central-South China are similar to that in Eastern China. (Fig. 5d). However, the growth rate of fertilizer use intensity in Central-South China is faster than that in East China since the inhibition of IOR and LIU is lower than that of East China.

(5) IOR and LIU effects reduce fertilizer use intensity in Southwest China (Fig. 5e). From 1997 to 2017, the reduction effect of IOR has been increasing, while the reduction effect of LIU has been weakening.

(6) Similar to the Southwest China, these two effects also reduce the fertilizer use intensity in the Northwest China, but the reduction is lower than in the Southwest China (Fig. 5f).

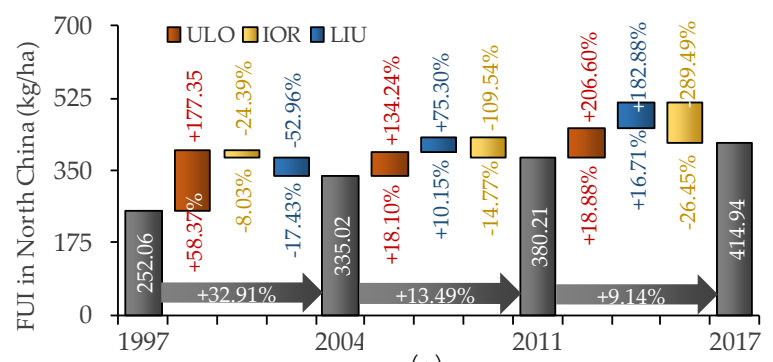

(a)
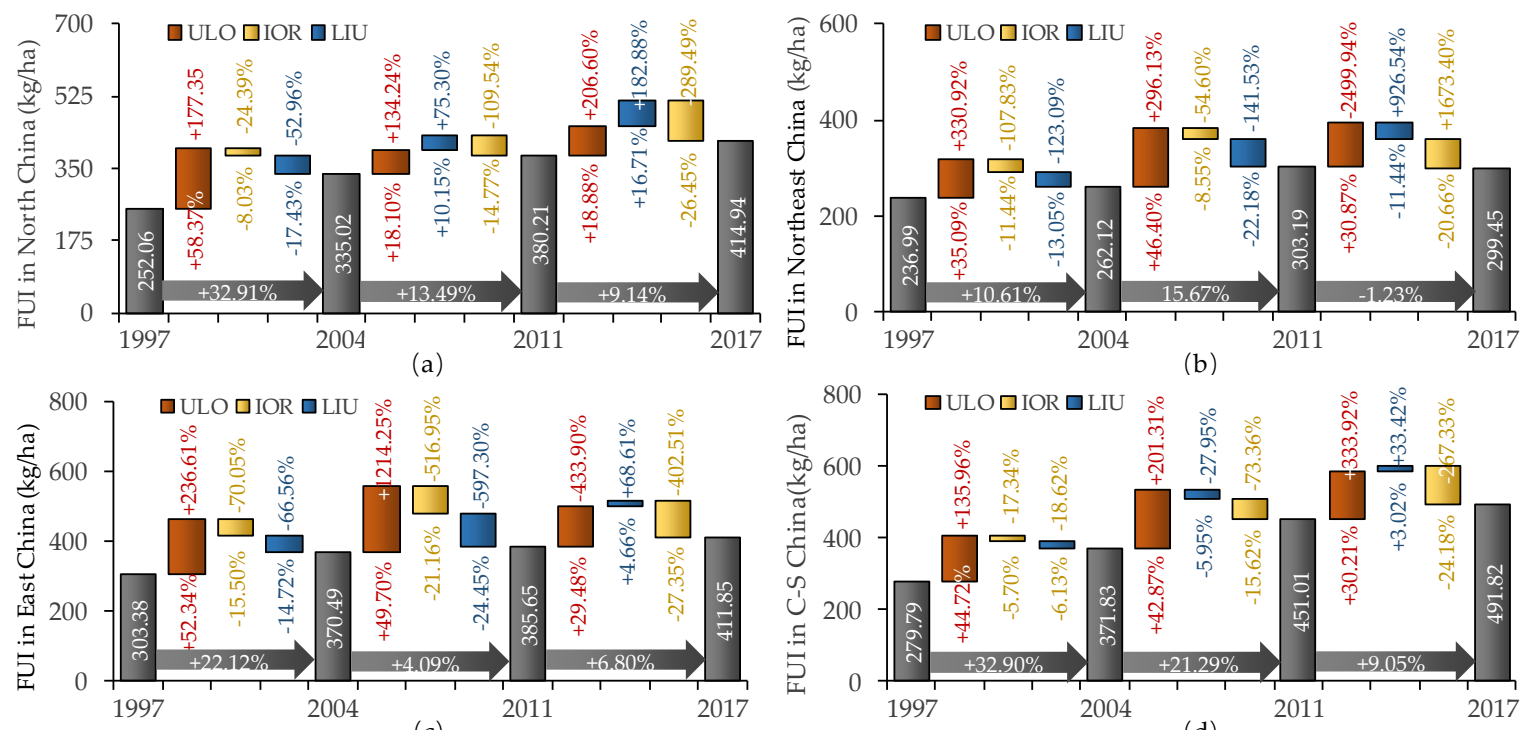

(c)

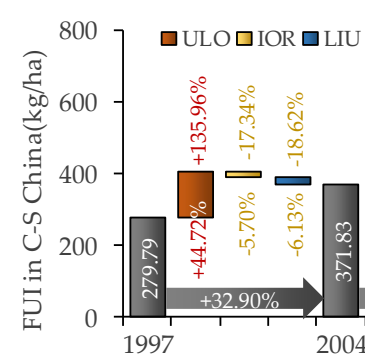

(b)
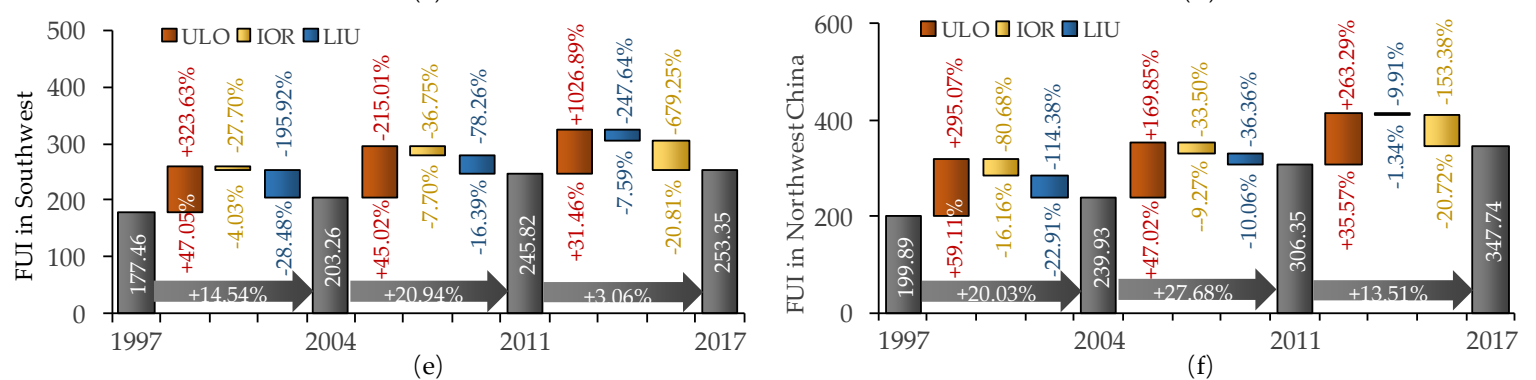

Figure 5. The contribution of fertilizer drivers in the six regions during the period 1997-2003, 2003-2009 and 2009-2017

In the figure, (a), (b), (c), (d), (e) and (f) represent the contribution of fertilizer drivers in the North China, Northeast, East China, Central South, Southwest, and Northwest China, respectively.

\subsection{Driving Factors for the Change of Four Kinds of Fertilizers Use Intensity}

\subsubsection{National Level Analysis}

Figure 6 shows the driving factors for the change in the use intensity of nitrogen, phosphate, potash and 
compound fertilizers at the national level. The use intensity of nitrogen fertilizer increased by $4.73 \%$ in $1997-$ 2004, which was mainly due to the contribution of ULO improvement. The effects LIU and IOR contributed negatively to the increase of nitrogen fertilizer use intensity, which indicated that the labor input and the fertilizer use efficiency restrained the increase of nitrogen fertilizer use intensity in this period. In addition, the main reason for the decrease of nitrogen fertilizer use intensity during 2004-2017 was the decrease of IOR. From the perspective of driving factors of phosphate fertilizer use intensity, the increase of $18.84 \%$ in 1997-2011 is mainly due to the improvement of labor productivity, while the decrease of $1.32 \%$ in 2011-2017 is mainly due to the decrease of labor input and the efficiency of phosphate fertilizer use. The reason why the use intensity of potash fertilizer increased steadily from 1997-2017 is that the labor productivity continued to rise. The fertilizer use intensity of compound fertilizer also continued to increase from 1997-2017. The main reason for the continuous increase of compound fertilizer use intensity is the increase of the labor productivity. At the same time, the IOR effect of compound fertilizer also promoted the increase of fertilizer use intensity during 19972011, which indicated that the fertilizer use efficiency of compound fertilizer was declining during this period. All in all, the improvement of ULO is still the most important pusher to promote the increase of fertilizer use intensity, but the IOR and LIU have more inhibition effect on the use intensity of four fertilizers (especially nitrogen fertilizer).
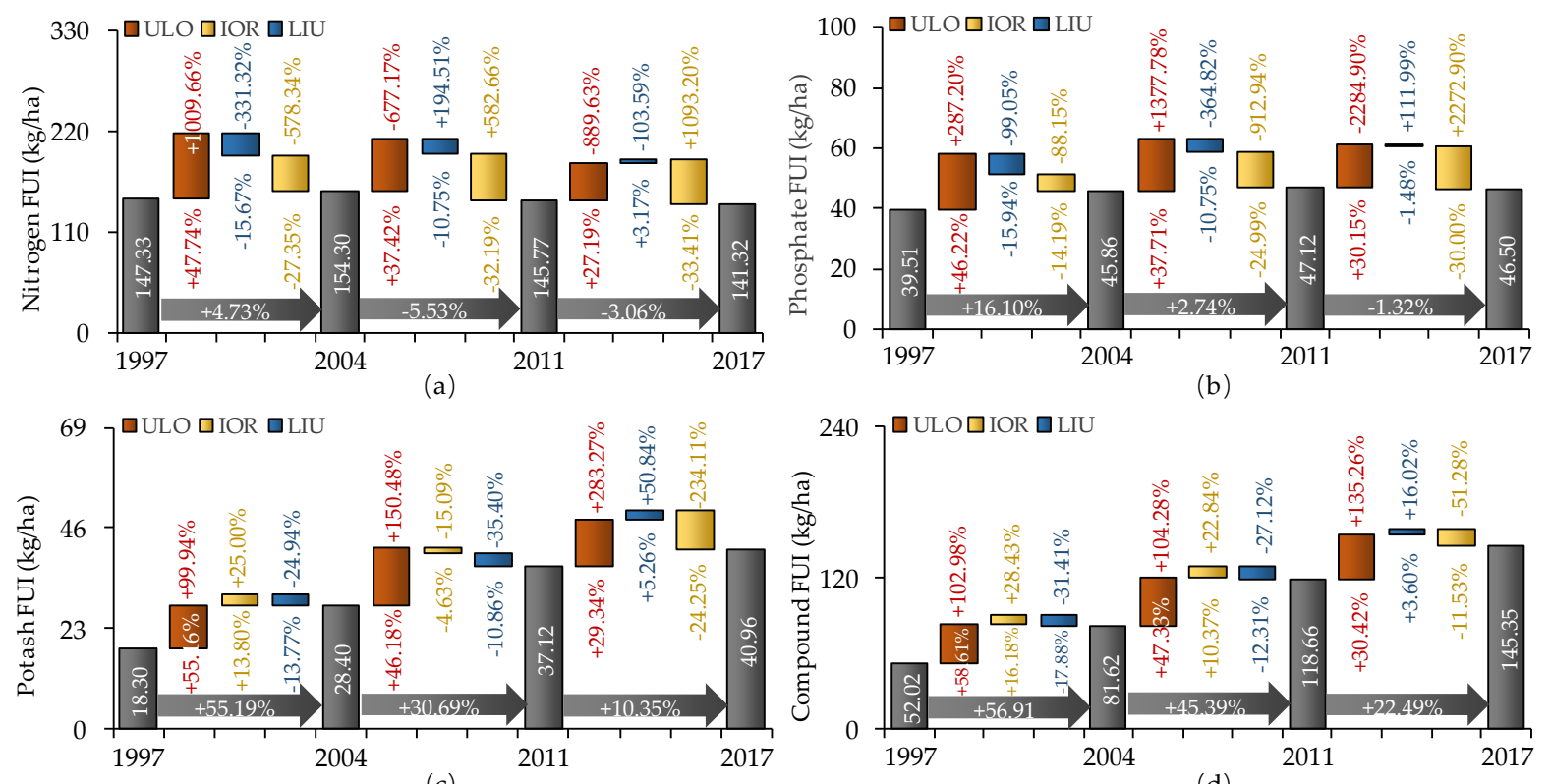

(c)

(d)

Figure 6. The contribution of four chemical fertilizers to the driving force of fertilizer application during 19972003, 2003-2009 and 2009-2017

(a), (b), (c) and (d) represent the driving factors and contribution rates of nitrogen, phosphorus, potassium and compound fertilizer fertilization intensity changes, respectively.

\subsubsection{Regional Level Analysis}

We further examine the driving factors of the changes in fertilizer use intensity at the regional level. Table 3 reports changes in fertilizer use intensity for each of the six regions from 1997 to 2017 and the average contribution rate of each driving factor.

(1) North China. From 1997 to 2017, the use intensity of nitrogen, phosphate, potash and compound fertilizers in North China increased by $15.80 \mathrm{~kg} / \mathrm{ha}, 9.77 \mathrm{~kg} / \mathrm{ha}, 21.54 \mathrm{~kg} / \mathrm{ha}$ and $116.17 / \mathrm{ha}$, respectively. The reason for the increase in the compound fertilizers use intensity is that the effect of IOR, ULO and LIU all contribute to the increase in the use intensity of compound fertilizer. Similarly, the three driving factors also promoted the increase of potash fertilizer use intensity. In addition, the use intensity of nitrogen and phosphate fertilizers increased the least, mainly because the reduced use of fertilizers due to increased fertilization efficiency offset the increased use of fertilizers due to increased labor productivity.

(2) Northeast China. From 1997 to 2017, the decrease of IOR was the main reason for the decrease of nitrogen and phosphate fertilizer use intensity in Northeast China by $41.62 \mathrm{~kg} / \mathrm{ha}$ and $2.62 \mathrm{~kg} / \mathrm{ha}$, respectively, 
while the other two driving factors increased the use intensity of nitrogen and phosphate fertilizers. In addition, the continuous increase in labor productivity promoted the use of potash and compound fertilizers in Northeast China, while the decrease in labor input inhibited the increase of potash fertilizer and the intensity of compound fertilizer use.

(3) East China. Together with the LIU effect, the IOR effect promoted the decline in nitrogen use intensity in East China from 1997 to 2017. The main reasons for the increase of the use intensity of phosphate fertilizer, potash fertilizer and compound fertilizer in 1997-2017 were the increase of ULO.

(4) Central-South China. From 1997 to 2017, the use intensity of nitrogen, phosphate, potash and compound fertilizers increased in this area, among which the use intensity of compound fertilizer increased the most (up to $131.41 \mathrm{~kg} / \mathrm{ha}$ ). The improvement of labor productivity promoted the increase of fertilizer use intensity of four kinds, while the other two driving factors restrained the increase of fertilizer application intensity.

(5) Southwest China. From 1997 to 2017, the use intensity of four kinds of fertilizers increased by $15.23 \mathrm{~kg} / \mathrm{ha}$, $8.87 \mathrm{~kg} / \mathrm{ha}, 11.21 \mathrm{~kg} / \mathrm{ha}$ and $39.70 \mathrm{~kg} / \mathrm{ha}$, respectively. The main reason is still the improvement of labor productivity. The effect of IOR and LIU restrained the increase of fertilization intensity of nitrogen, phosphate and potash fertilizers. In addition, the IOR promoted the increase of compound fertilizer use intensity, which indicated that the fertilization efficiency of compound fertilizer in this area needed to be improved.

(6) Northwest China. From 1997-2017, the use intensity of nitrogen fertilizer in Northwest China decreased by $74.67 \mathrm{~kg} / \mathrm{ha}$. The effect of IOR and LIU jointly promoted the decline of nitrogen fertilizer use intensity. Northwest China is the gathering place in the upstream of the water source. Reducing the use of nitrogen fertilizer will protect the water source. However, the use intensity of phosphate fertilizer, potash fertilizer and compound fertilizer increased by $13.77 \mathrm{~kg} / \mathrm{ha}, 22.98 \mathrm{~kg} / \mathrm{ha}$ and $81.06 \mathrm{~kg} / \mathrm{ha}$, respectively. ULO is a factor that drives the increase in use intensity of these three fertilizers.

Table 3. Driving factors for the change of four kinds of fertilizer use intensity in six regions

\begin{tabular}{|c|c|c|c|c|c|c|c|}
\hline Fertilizer species & Investigation Indicators & $\mathrm{NC}$ & NE & EC & CS & SW & NW \\
\hline \multirow{4}{*}{ Nitrogen fertilizer } & $\Delta \mathrm{F}$ & 15.80 & -41.62 & -4.46 & 31.30 & 15.23 & -74.67 \\
\hline & IOR & -920.39 & 291.35 & 3634.94 & -386.35 & -433.82 & 272.67 \\
\hline & ULO & 873.58 & -310.25 & -4844.57 & 535.66 & 908.07 & -244.46 \\
\hline & LIU & 146.81 & 118.90 & 1309.64 & -49.31 & -374.25 & 71.78 \\
\hline \multirow{4}{*}{ Phosphate fertilizer } & $\Delta \mathrm{F}$ & 9.77 & -2.62 & 3.59 & 6.25 & 8.87 & 13.77 \\
\hline & IOR & -296.18 & 698.65 & -1143.49 & -681.38 & -207.73 & -193.21 \\
\hline & ULO & 413.03 & -940.42 & 1680.38 & 933.21 & 502.51 & 396.04 \\
\hline & LIU & -16.85 & 341.77 & -436.89 & -151.83 & -194.78 & -102.83 \\
\hline \multirow{4}{*}{ Potash fertilizer } & $\Delta \mathrm{F}$ & 21.54 & 11.29 & 18.78 & 43.09 & 11.21 & 22.98 \\
\hline & IOR & 8.33 & -28.80 & -116.66 & -44.11 & -2.52 & 24.49 \\
\hline & ULO & 83.68 & 220.27 & 249.61 & 143.66 & 163.83 & 87.94 \\
\hline & LIU & 7.98 & -91.47 & -32.94 & 0.45 & -61.31 & -12.43 \\
\hline \multirow{4}{*}{ Compound fertilizer } & $\Delta \mathrm{F}$ & 116.17 & 95.36 & 90.58 & 131.41 & 39.70 & 81.06 \\
\hline & IOR & 2.32 & 32.08 & -6.59 & -0.45 & 22.33 & -1.28 \\
\hline & ULO & 71.48 & 125.57 & 147.51 & 101.15 & 129.58 & 122.62 \\
\hline & LIU & 26.19 & -57.65 & -40.92 & -0.69 & -51.91 & -21.34 \\
\hline
\end{tabular}

\section{Discussion}

This article extends previous studies on the driving factors for the change in fertilizer use intensity. On the one hand, the effects of input-output ratio, labor productivity and labor input on the change of fertilizer use intensity were investigated. On the other hand, the driving factors for the change of fertilizer use intensity in China's six regions were compared and analyzed. Knowledge about reducing the use of chemical fertilizers has been supplemented, which also provides a reference for reducing the use of chemical fertilizers in different regions.

The conclusion of this paper is that labor productivity promotes the increase of fertilizer use intensity, which is consistent with previous studies on low fertilizer use and low productivity in a certain area (Lambrecht et al., 2014; Mwangi, 1996). These researches have shown that farmers use chemical fertilizers to get more output, which in turn increases labor productivity (Mwangi, 1996). Therefore, in order to obtain more yield, farmers often use more fertilizers. The discovery that the input-output ratio effect of chemical fertilizers can reduce the intensity of fertilizer use has been confirmed by many literatures on fertilization efficiency(Ma et al., 2014). Because of the improvement of fertilization technology in agricultural production, fertilization efficiency has been improved, 
such as changing fertilization methods (Rahman and Zhang, 2018), promoting the use of controlled-release fertilizer (Shaviv and Mikkelsen, 1993), and improving soil fertilizer management (Zhang et al., 2011).

As for the effect of labor input per unit sown area, our study found that the effect of reduced labor input on the change of fertilizer use intensity will change over time. On the one hand, the intensity of fertilizer use will decrease with the decrease of labor input at the early stage of labor transfer (at least before 2004). The main reason for the low efficiency of agricultural production in China is the widespread existence of smallholder farms (Adamopoulos and Restuccia, 2014). Non-agricultural employment of rural labor force will promote the expansion of farm scale (Ju et al., 2016) , improve fertilizer use efficiency(Ma et al., 2014), and reduce fertilizer use. In addition, although fertilizer use per unit land is decreasing, more serious problems may arise. The fragmentation of land (Xie and Lu, 2017) and the loss of labor force will make farmers no longer pay attention to the income brought by farmland labor(Shi et al., 2011), and will also lead to the phenomenon of abandonment of farmland in some places (Deng et al., 2018). On the other hand, with the passage of time, the decreasing of labor input will increase the use of chemical fertilizer. Lamb (2003) analyzed the substitution relationship between agricultural labor input and fertilizer use in India, and confirmed that farmers would use more fertilizer in the field if they chose non-agricultural employment. Zhang et al. (2013) argued that the phenomenon of 'part-time farmers' in China would lead to excessive use of nitrogen fertilizer. At present, China's rural labor force is losing continuously, and the rural labor force is gradually feminized and aging (Chang et al., 2011). This will lead to the inability of organic fertilizers such as animal manure to be transported to the field, thus increasing the use of chemical fertilizers in the field(Chadwick et al., 2012). In addition, some scholars have directly confirmed that the migration of labor per hectare does increase fertilizer use(Ebenstein et al., 2011). At the present stage of China's development, the continuous loss of agricultural labor force has been unable to reduce the use of chemical fertilizers. Under the condition of ensuring that farmers' interests are not lost, expanding the scale of farm management through land transfer and other means may be an important way to solve agricultural pollution, abandon farmland and improve agricultural production efficiency.

There may be some possible limitations in this study. On the one hand, this paper compares and analyzes the driving factors for the change of fertilizer use intensity in the six regions, but there will be heterogeneity within the six regions. For example, the Central-Southern China include temperate, subtropical, and tropical zones, and differences in temperature zones have a greater impact on fertilizer use intensity. On the other hand, China lacks data on the number of employees in the planting industry, which is calculated by the ratio of gross plantation output to primary industry gross domestic product. This is therefore subject to biases and confounding that may have influenced our model estimates. However, fertilizer consumption mainly comes from crop production, so we will continue to follow up this data in the future to obtain more reliable results.

\section{Conclusions}

Although the Chinese government has taken a series of measures to reduce fertilization, the fertilizer use intensity in China is still increasing. Among the four kinds of fertilizers, only nitrogen fertilizer use intensity is decreasing, while phosphate fertilizer, potash fertilizer and compound fertilizer use intensity is still showing an upward trend. In terms of the driving factors for the change in overall fertilizer use intensity, the improvement of labor productivity is always the main driving factor of the change of overall fertilizer use intensity, whether at the national level or at the regional level. Therefore, the increase of labor productivity is closely related to the increase of fertilization intensity. Agricultural practitioners in China rely more on fertilization to increase crop yields. It is urgent to reduce the fertilization intensity in China by changing the mode of production and fertilization methods of agricultural practitioners. All in all, the input-output ratio effect reduces the fertilizer use intensity in different regions of China, while the labor input effect per unit sowing area has a dual effect of inhibition and promotion on the increase of fertilizer use intensity.

We also explored the driving factors for the changes of 4 kinds of fertilizer use intensity. From the national level, the fertilizer input-output ratio effect is the main reason for the decrease of nitrogen and phosphorus fertilizer use intensity in 2004-2017, while the increase of labor productivity is the most important factor for the increase of potash fertilizer and compound fertilizer use intensity in 1997-2017. From the regional level, the main factors for the decreased of the nitrogen fertilizer use intensity in Northeast, East China and Northwest China are the input-output ratio effect and the labor inputs per unit sown area effect. In addition, the main reason for the increase of nitrogen fertilizer use intensity in East China, Central-South China and Southwest China is the increase of labor productivity. The decrease of phosphate fertilizer use intensity in Northeast China is the result of both input-output ratio effect and labor input effect per unit sown area. The main reason for the increase of phosphate fertilizer use intensity in the other five regions is the increase of labor productivity. Labor productivity is the main factor causing the increase of potash fertilizer and compound fertilizer use intensity in different regions. 
Therefore, to control the growth of China's fertilizer application intensity and reduce the amount of fertilizer per unit of cultivated land, we must improve the fertilization efficiency and reduce the labor input per unit sowing area. In particular, we must make the improvement of labor productivity no longer rely on chemical fertilizer input. These measures must be strengthened in central and southern China and the amount of nitrogen fertilizer.

Funding: This study has received funding from Research on the Realization Mechanism of Agricultural Socialization Service to Agricultural Scale Operation under the Background of Rural Revitalization (YTSK2021-149).

Acknowledgments: We are grateful for the support about workplace from the Economic Growth \& Green Development Academic Team in Shandong University of Finance and Economics.

\section{References}

Adamopoulos, T., \& Restuccia, D. (2014). The size distribution of farms and international productivity differences. Am. Econ. Rev., 104, 1667-1697. https://doi.org/10.1257/aer.104.6.1667

Atafar, Z., Mesdaghinia, A., Nouri, J., Homaee, M., Yunesian, M., Ahmadimoghaddam, M., \& Mahvi, A. H. (2010). Effect of fertilizer application on soil heavy metal concentration. Environ. Monit. Assess, 160, 83. https://doi.org/10.1007/s10661-008-0659-x

Ayoola, O., \& Adeniyan, O. (2006). Influence of poultry manure and NPK fertilizer on yield and yield components of crops under different cropping systems in south west Nigeria. Afr. J. Biotechnol., 5.

Cai, J., Xia, X., Chen, H., Wang, T., \& Zhang, H. (2018). Decomposition of Fertilizer Use Intensity and Its Environmental Risk in China's Grain Production Process. Sustainability, 10, 498. https://doi.org/10.3390/su10020498

Chadwick, D., Chen, Q., Tong, Y., Yu, G., \& Shen, Q. (2012). Improving manure nutrient management towards sustainable intensification in China. UK-China Sustainable Agriculture Innovation Network.

Chang, H., Dong, X. Y., \& MacPhail, F. (2011). Labor Migration and Time Use Patterns of the Left-behind Children and Elderly in Rural China. World Dev., 39, 2199-2210. https://doi.org/10.1016/j.worlddev.2011.05.021

Chen, X., Cui, Z., Fan, M., Vitousek, P., Zhao, M., Ma, W., Yang, J. (2014). Producing more grain with lower environmental costs. Nature, 514, 486. https://doi.org/10.1038/nature13609

Chen, X., Ma, L., Ma, W., Wu, Z., Cui, Z., Hou, Y., \& Zhang, F. (2018). What has caused the use of fertilizers to skyrocket in China? Nutr. Cycl. Agroecosys., 110, 241-255. https://doi.org/10.1007/s10705-017-9895-1

Chien, S. H., Prochnow, L. I., \& Cantarella, H. (2009). Recent Developments of Fertilizer Production and Use to Improve Nutrient Efficiency and Minimize Environmental Impacts. Adv. Agron., 102, 267-322. https://10.1016/s0065-2113 (09)01008-6

Coomes, O. T., Barham, B. L., MacDonald, G. K., Ramankutty, N., \& Chavas, J. P. (2019). Leveraging total factor productivity growth for sustainable and resilient farming. Nature Sustainability, 2, 22. https://doi.org/10.1038/s41893-018-0200-3

Cui, Z., Zhang, H., Chen, X., Zhang, C., Ma, W., Huang, C., Li, X. (2018). Pursuing sustainable productivity with millions of smallholder farmers. Nature, 555, 363. https://doi.org/10.1038/nature25785

Deng, X., Xu, D., Qi, Y., \& Zeng, M. (2018). Labor off-farm employment and cropland abandonment in rural china: Spatial distribution and empirical analysis. Int. J. Env. Res. Pub. He., 15, 1808. https://doi.org/10.3390/ijerph15091808

Ebenstein, A., Zhang, J., McMillan, M. S., \& Chen, K. (2011). Chemical fertilizer and migration in China; National Bureau of Economic Research. https://doi.org/10.3386/w17245

Guo, J. H., Liu, X. J., Zhang, Y., Shen, J., Han, W., Zhang, W., Zhang, F. (2010). Significant acidification in major Chinese croplands. Science, 327, 1008-1010. https://doi.org/10.1126/science.1182570

HUANG, S. A., Sheng-min, S., \& Ming-bo, G. (2005). The impact of land ownership structure on agricultural economic growth: an empirical analysis on agricultural production efficiency on the Chinese mainland (1949-1978). Social Science in China, 3, 38-47.

Jayne, T. S., Mather, D., Mason, N., \& Ricker-Gilbert, J. (2013). How do fertilizer subsidy programs affect total fertilizer use in sub-Saharan Africa? Crowding out, diversion, and benefit/cost assessments. Agr. Econ., 44, 687-703. https://doi.org/10.1111/agec.12082 
Ju, X. T., Xing, G. X., Chen, X. P., Zhang, S. L., Zhang, L. J., Liu, X. J., ... Zhu, Z. L. (2009). Reducing environmental risk by improving $\mathrm{N}$ management in intensive Chinese agricultural systems. P. Natl. Acad. Sci. USA, 106, 3041-3046. https://doi.org/10.1073/pnas.0813417106

Ju, X., Gu, B., Wu, Y., \& Galloway, J. N. (2016). Reducing China's fertilizer use by increasing farm size. Global Environ. Chang., 41, 26-32. https://doi.org/10.1016/j.gloenvcha.2016.08.005

Lamb, R. L. (2003). Fertilizer use, risk, and off-farm labor markets in the semi-arid tropics of India. Am. J. Agr. Econ., 85, 359-371. https://doi.org/10.1111/1467-8276.00125

Lambrecht, I., Vanlauwe, B., Merckx, R., \& Maertens, M. (2014). Understanding the Process of Agricultural Technology Adoption: Mineral Fertilizer in Eastern DR Congo. World Dev., 59, 132-146. https://doi.org/10.1016/j.worlddev.2014.01.024

Li, Y., Zhang, W., Ma, L., Huang, G., Oenema, O., Zhang, F., \& Dou, Z. (2013). An Analysis of China's Fertilizer Policies: Impacts on the Industry, Food Security, and the Environment. J. Environ. Qual., 42, 972-81. https://doi.org/10.2134/jeq2012.0465

Liu, X., Zhang, Y., Han, W., Tang, A., Shen, J., Cui, Z., Christie, P. (2013). Enhanced nitrogen deposition over China. Nature, 494, 459. https://doi.org/10.1038/nature11917

Lu, H., Xie, H., Lv, T., \& Yao, G. (2019). Determinants of cultivated land recuperation in ecologically damaged areas in China. Land Use Policy, 81, 160-166. https://doi.org/10.1016/j.landusepol.2018.10.052

Ma, L., Feng, S., Reidsma, P., Qu, F., \& Heerink, N. (2014). Identifying entry points to improve fertilizer use efficiency in Taihu Basin, China. Land Use Policy 37, 52-59. https://doi.org/10.1016/j.landusepol.2013.01.008

Ma, L., Velthof, G. L., Wang, F. H., Qin, W., Zhang, W. F., Liu, Z., ... Zhang, F. S. (2012). Nitrogen and phosphorus use efficiencies and losses in the food chain in China at regional scales in 1980 and 2005. Sci. Total Environ., 434, 51-61. https://doi.org/10.1016/j.scitotenv.2012.03.028

Majumdar, D., \& Gupta, N. (2000), Nitrate pollution of groundwater and associated human health disorders. Indian J. Environ. health, 42, 28-39

Mosier, A., Syers, J. K., \& Freney, J. R. (2013). Agriculture and the nitrogen cycle: assessing the impacts of fertilizer use on food production and the environment. Island Press, 65.

Murgai, R. (1999). The Green Revolution and the productivity paradox: evidence from the Indian Punjab. The World Bank. https://doi.org/10.1596/1813-9450-2234

Mustapha, A. B., \& Said, R. (2016). Factors influencing fertilizer demand in developing countries: evidence from Malawi. Journal of Agribusiness in Developing and Emerging Economies, 6, 59-71. https://doi.org/10.1108/JADEE-10-2013-0040

Mwangi, W. M. (1996). Low use of fertilizers and low productivity in sub-Saharan Africa. Nutr. Cycl. Agroecosys, 47, 135-147. https://doi.org/10.1007/BF01991545

Pan, D. (2014). The spatial-temporal difference of driving effects for fertilizer use intensity change and its determinants in China. Econ. Geogr. 34, 121-126.

Prasad, R. (1998). Fertilizer urea, food security, health and the environment. Curr. Sci., 75, 677-683.

Rahman, K., \& Zhang, D. (2018). Effects of fertilizer broadcasting on the excessive use of inorganic fertilizers and environmental sustainability. Sustainability, 10, 759. https://doi.org/10.3390/su10030759

Savci, S. (2012). An agricultural pollutant: chemical fertilizer. Int. J. Env. Sci. Dev., 3, 73. https://doi.org/10.7763/IJESD.2012.V3.191

Shaviv, A., \& Mikkelsen, R. (1993). Controlled-release fertilizers to increase efficiency of nutrient use and minimize environmental degradation-A review. Fertilizer research, 35, 1-12. https://doi.org/10.1007/BF00750215

Shi, X., Heerink, N., \& Qu, F. (2011). Does off-farm employment contribute to agriculture-based environmental pollution? New insights from a village-level analysis in Jiangxi Province, China. China Econ. Rev., 22, 524-533. https://doi.org/10.1016/j.chieco.2010.08.003

Smith, L. E. D., \& Siciliano, G. (2015). A comprehensive review of constraints to improved management of fertilizers in China and mitigation of diffuse water pollution from agriculture. Agr. Ecosyst. Environ., 209, 15-25. https://doi.org/10.1016/j.agee.2015.02.016 
Snyder, C., Bruulsema, T., Jensen, T., \& Fixen, P. (2009). Review of greenhouse gas emissions from crop production systems and fertilizer management effects. Agr. Ecosyst. Environ. 133, 247-266. https://doi.org/10.1016/j.agee.2009.04.021

Stewart, W., Dibb, D., Johnston, A., \& Smyth, T. (2005). The contribution of commercial fertilizer nutrients to food production. Agron. J., 97, 1-6. https://doi.org/10.2134/agronj2005.0001

Sun, B., Zhang, L., Yang, L., Zhang, F., Norse, D., \& Zhu, Z. (2012). Agricultural non-point source pollution in China: causes and mitigation measures. Ambio, 41, 370-379. https://doi.org/10.1007/s13280-012-0249-6

Sun, J. (1998) Accounting for energy use in China, 1980-1994. Energy, 23, 835-849. https://doi.org/10.1016/S0360-5442(98)00031-0

Tilman, D., Fargione, J., Wolff, B., D'antonio, C., Dobson, A., Howarth, R., Swackhamer, D. (2001). Forecasting agriculturally driven global environmental change. Science, 292, 281-284. https://doi.org/10.1126/science.1057544

Van Damme, M., Clarisse, L., Whitburn, S., Hadji-Lazaro, J., Hurtmans, D., Clerbaux, C., \& Coheur, P. F. (2018). Industrial and agricultural ammonia point sources exposed. Nature, 564, 99. https://doi.org/10.1038/s41586-018-0747-1.

Vanlauwe, B., \& Giller, K. E. (2006). Popular myths around soil fertility management in sub-Saharan Africa. Agr. Ecosyst. Environ., 116, 34-46. https://doi.org/10.1016/j.agee.2006.03.016

Wu, Y., Xi, X., Tang, X., Luo, D., Gu, B., Lam, S. K., Vitousek, P. M., \& Chen, D. (2018). Policy distortions, farm size, and the overuse of agricultural chemicals in China. P. Natl. Acad. Sci. USA, 115, 7010-7015. https://doi.org/10.1073/pnas.1806645115

Xie, H., \& Lu, H. (2017). Impact of land fragmentation and non-agricultural labor supply on circulation of agricultural land management rights. Land Use Policy, 68, 355-364. https://doi.org/10.1016/j.landusepol.2017.07.053

Zhang, F., Cui, Z., Fan, M., Zhang, W., Chen, X., \& Jiang, R. (2011). Integrated soil-crop system management: reducing environmental risk while increasing crop productivity and improving nutrient use efficiency in China. J. Environ. Qual., 40, 1051-1057. https://doi.org/10.2134/jeq2010.0292

Zhang, W., Cao, G., Li, X., Zhang, H., Wang, C., Liu, Q., Jiang, R. (2016). Closing yield gaps in China by empowering smallholder farmers. Nature, 537, 671. https://doi.org/10.1038/nature19368

Zhang, W. F., Dou, Z. X., He, P., Ju, X. T., Powlson, D., Chadwick, D., \& Zhang, F. S. (2013). New technologies reduce greenhouse gas emissions from nitrogenous fertilizer in China. P. Natl. Acad. Sci. USA, 110, 8375-80. https://doi.org/10.1073/pnas.1210447110

Zhang, Y., Yin, C., Cao, S., Cheng, L., Wu, G., \& Guo, J. (2018). Heavy metal accumulation and health risk assessment in soil-wheat system under different nitrogen levels. Sci. Total Environ., 622, 1499-1508. https://doi.org/10.1016/j.scitotenv.2017.09.317

Zheng, W., \& Xu, X. (2017). Decomposition of driving factors and analysis of influencing factors on the change of chemical fertilizer intensity in Jiangsu Province. J. Huazhong Agric. Univ., 8.

Zhu, Z., \& Chen, D. (2002). Nitrogen fertilizer use in China-Contributions to food production, impacts on the environment and best management strategies. Nutr. Cycl. Agroecosys., 63, 117-127. https://doi.org/10.1023/A:102110702

\section{Copyrights}

Copyright for this article is retained by the author(s), with first publication rights granted to the journal.

This is an open-access article distributed under the terms and conditions of the Creative Commons Attribution license (http://creativecommons.org/licenses/by/4.0/). 